\title{
2. Tadftrag.
}

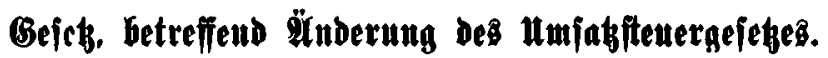

Bom 30. Rovember 1922 (RSBl. Reil I S. 890).

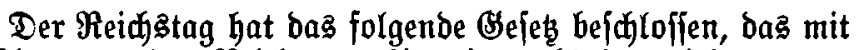

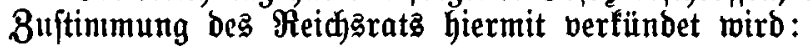

\section{$\mathfrak{A r t i f e l} I$.}

Das Umfagitenrergeféz nom 24. Dezember 1919 (RSBBr.

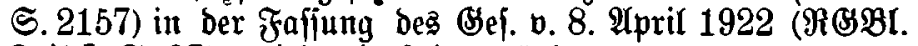
Teil I 5.373 ) wiro wie folgt geändert:

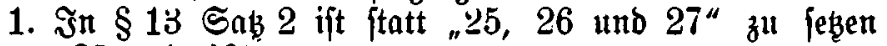
"25 unb 26 ".

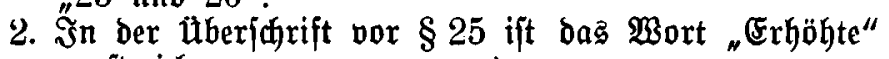
zu f́treidjen.

3. $\$ 27$ erfält folgende ₹affung:

$\$ 27$.

Die Stener fïr bie $\mathfrak{u}$ bernahme von $\mathfrak{A}$ nzeigen nad) $\S 26$ ermäß̄igt fid bei Beitungen und Beitidriften

von den eriten 1 Mifllion Mart dez immerhalb eines

Sialendervierteljahres vereinnahimten (Entgelts auf $1 / 2$ vom Şundert,

von ben nä山jten 1 Million $\mathfrak{M a r k}$ dez innerhalb eines

Ralenbervierteljahro vereinnahmten Entgelta auf 1 vom Şunbert,

von ben nädiften 1 Million Marf bez innerhalb eines

Ralendervierteljahrs vereinnahmten Entgelte auf $1^{1 / 1}$ vom Şunbert,

von ben barüber hinauşgchenden Beträgen auf 2 vom Sundert.

Bibt ein Steuerpflidtiger mehrere Beitungen ober Beit= iquiften heraus, io ift für bie etrwaige Ermäßigung jebe Zeitung und jeó Beitjarift felfftändig zu behanbeln."

\section{$\mathfrak{A} r$ tifel II.}

Die Boriðuriften bes $\mathfrak{A}$ rtifelaz I treten mit Birfung vom 1. Jumuar 1922 in Rraft.

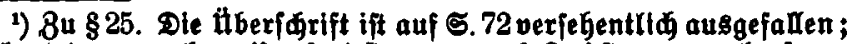

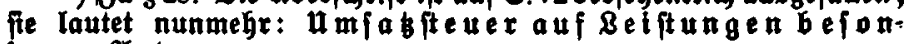
berex Prt. 
